\title{
Global Interaction into the Traditional Design Studios through Blogs
}

\author{
By Jill Bouratoglou* \\ Lia Dikigoropoulou ${ }^{\dagger}$
}

Special teaching methods used in an advanced design course, looks to enrich a student's experience by increasing the number of contact hours between student and online reviewers located around the world. In this design studio we try to bring global interaction into the traditional classroom through blogs. A blog is a chronological discussion or publication on the world-wide web. During the entire semester the students are required to keep all their research and design process on their own blog. Their research and work is shown on their blog through diagrams, drawings, sketches, images of models and text. Each student follows one another's blogs to see their work and give comments. The blogs create a virtual studio culture that connects the students to the professional world. All of the work of the students from research to design is posted on a biweekly basis online. Each student is assigned one to three online reviewers to follow their work on their blogs for the entire semester. Each online reviewer is a professional architect or designer with specialties that align with the projects of our students. They are located all around the world bringing a variety of ideas, projects, and cultural experiences. A formal dialogue is setup between each student and the online reviewer who acts as a critic throughout the semester. This connection of the students and the professional world rarely occurs. This is a unique and innovative way of connecting a design studio with professionals from all over the world. We have found blogs to be an important part of our studio environment. Blogs:

- Present, organize and protect students' work as a digital portfolio.

- Are a chronological arrangement of information and research.

- Create a dialog between the students and critics.

- Introduce a new skill of being part of global society.

- Expose student to alternative ways of thinking.

- Reinforce writing and promote discussion.

- Allow fellow students and professors to see work even when not in the studio.

- Allow students accessibility to a design critique twenty four hours a day.

- Create a studio at virtually anytime, at any place as long as there is internet access.

- Extend the classroom beyond the boundaries of the campus.

*Associate Professor, New York City College of Technology, USA.

${ }^{\dagger}$ Assistant Professor, New York City College of Technology, USA. 
- Provide students with new and unique references that are not familiar with through the online reviewers.

- Connect students with professionals throughout the world.

- Connect professors with other professionals.

\section{Introduction}

Figure 1. Locations of Online Reviewers

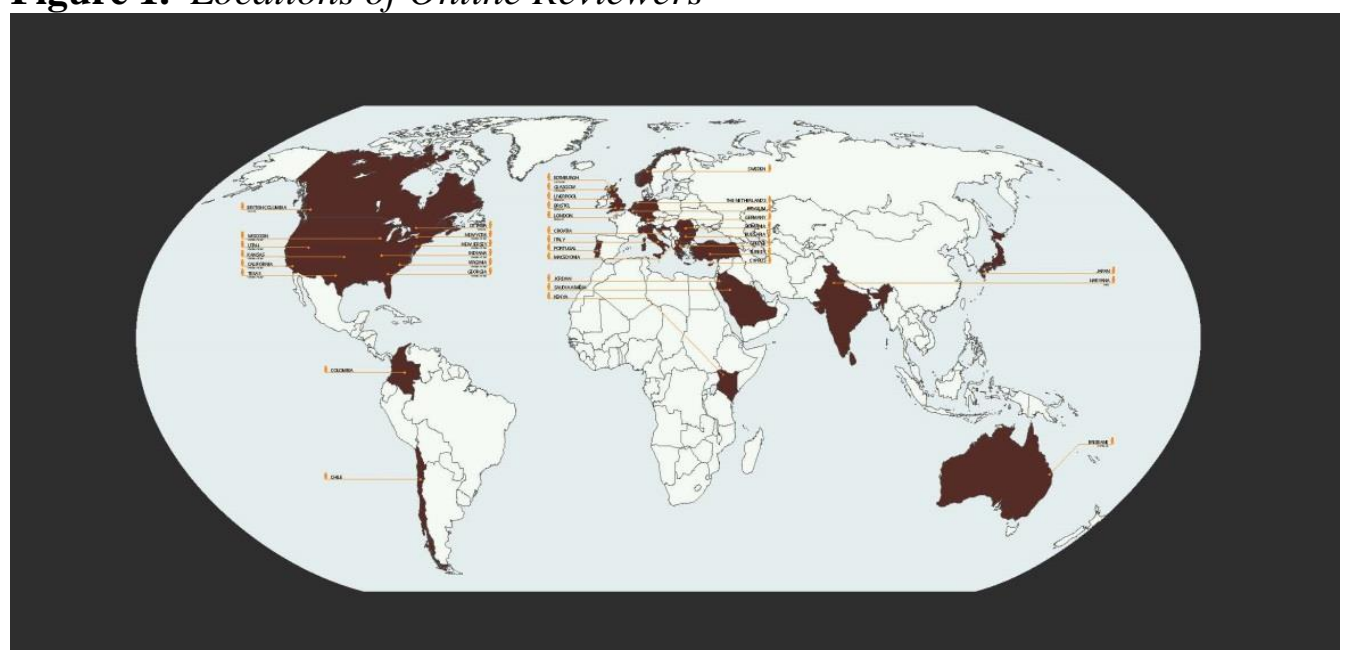

Goal

Connecting Our Students to the Outside World Using Online Reviewers and Student Blogs in the Classroom

\section{Course Format}

Students select a building type to research, program and design, documenting their process throughout the semester.

This is a documentation of the process we use in an advanced design studio. The project emphasis is on a more complex building organization, and the primary emphasis is in the further development and exploration of design principles involved in creating appropriate architecture, focusing on the integration of program, context, site, composition and space planning.

\section{Online Blog}

Blogs are individual websites that are updated by an author. They follow a chronological order and allow others to post comments and follow.

Why Do we Use Blogs in the Classroom?

- Blogs organize and protect students work as a digital portfolio

- Present a chronological arrangement of information

- Introduce a new skill of being part of global society

- Expose to alternative ways of thinking

- Reinforce writing and promote discussion 
- Follow classmates work even when not at the studio

How Do we Use Blogs?

- Each student creates their blog the first day of class.

- They have assignments that they must post to their blogs.

- They add the professors to the blog which allows us to follow and review their work as well as leave comments.

- Online Reviewers are assigned.

\section{Online Reviewers}

Each semester we send emails to the former online reviewers asking if they would like to participate again. We have found the online reviewers using social media.

Why Do we Use Blogs?

- Students have access to a design critique at any time. Not only during class time.

- Creates a studio at virtually anytime, at any place as long as there is internet access.

- It extends the classroom beyond the boundaries of the campus.

- Connect students with professionals throughout the world.

- Online reviewers give references from their perspectives that the class may not be familiar with.

- Connects Professors with other professionals.

We have been using blogs with our students for the past twelve semesters. We currently have a pool of about one hundred online reviewers.

\section{Blogs Assignments Calendar}

At the beginning of each class, students are given an assignment.

The students must post the completed assignment to their blog by the next class. Concurrently the assignment is emailed to the online reviewers so they get familiar with the syllabus and have a better understanding of what the students are posting. 
Vol. 1, No. 2 Bouratoglou et al.: Global Interaction into the Traditional Design...

Figure 2. List of Assignments-Sample

\begin{tabular}{|c|c|c|}
\hline $\begin{array}{l}\text { ASSIGNMENT } \\
\text { NUMBER }\end{array}$ & ASSIGNMENT & $\begin{array}{l}\text { DUE } \\
\text { DATE }\end{array}$ \\
\hline 1 & Site Analysis & $02 / 04 / 2013$ \\
\hline 2 & $\begin{array}{l}\text { Each student is to create a class blog. Answer questions on Typology, and } \\
\text { provide } 10 \text { case study examples of their building type choice. Site analysis, } \\
\text { and typology materials are to be posted on the individual blogs }\end{array}$ & $02 / 13 / 2013$ \\
\hline 3 & Find and analyze 10 examples of Parti + Massing, post examples to blog. & $02 / 20 / 2013$ \\
\hline 4 & Research 10 examples of Symmetry + Hierarchy, post examples to blog. & $02 / 25 / 2013$ \\
\hline 5 & $\begin{array}{c}\text { Find } 10 \text { examples of Geometry + Natural Lighting + Structure, post } \\
\text { examples to blog. }\end{array}$ & $02 / 27 / 2013$ \\
\hline 6 & $\begin{array}{l}\text { Provide } 10 \text { examples of Public vs. Private space planning + Circulation } \\
+ \text { + Approach, post examples to blog. }\end{array}$ & $03 / 04 / 2013$ \\
\hline 7 & $\begin{array}{l}\text { Research } 10 \text { examples of space organization and make color coded } \\
\text { diagrams showing each space location and scale, post examples to blog. }\end{array}$ & $03 / 11 / 2013$ \\
\hline 8 & Building program analysis based on precedent studies & $03 / 13 / 2013$ \\
\hline 9 & Concept Design & $03 / 18 / 2013$ \\
\hline 10 & Concept Design / 3 Dimensional Interpretation of Collage & $03 / 20 / 2013$ \\
\hline \multicolumn{3}{|c|}{ SPRING BREAK: 03/25/2013 - 04/02/2013 } \\
\hline \multicolumn{3}{|c|}{ MID SEMESTER EVALUATION: 4/15/2013 } \\
\hline 11 & Programatic Study \& Development & $04 / 22 / 2013$ \\
\hline 12 & Refinement of Massing Studies & $04 / 24 / 2013$ \\
\hline 13 & Refinement of Plans \& Sections & $05 / 01 / 2013$ \\
\hline 14 & Development of Exterior Elevations \& Fenestration & 05/08/2013 \\
\hline \multicolumn{3}{|c|}{ FINAL PRESENTATION: 5/20/2013 } \\
\hline
\end{tabular}

Figure 3. Example of Site

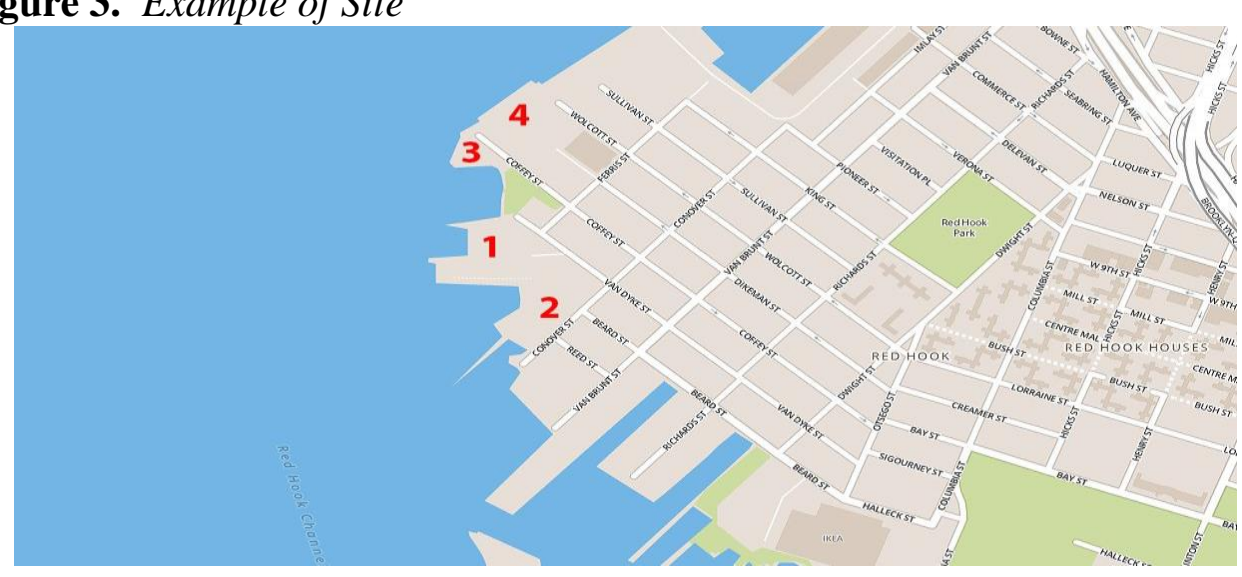




\section{Assignment 1 Site Analysis}

Objective: Students will analyze social patterns, behaviors, flows and narratives specific to the sites in a chosen neighborhood in New York City. Initially, student groups will form, to collaborate and graphically document site-specific characteristics.

Structure: Students work in groups, and produce analytical site mappings/diagrams. They create a blog that will house all the collaborative documentation for each group's site analysis. This blogs will be available for each student to use for reference throughout the semester.

Each group collectively generates the following documentation:

SITE: Location- The site needs to be connected to existing major streets or landmarks. Aerial photographs help in this assessment stage. There should be documentation of distances and time from familiar reference points. major places

SITE: Generalities-Includes, figure ground diagram, neighborhood context, green space, places of interaction, accessibility, schools, places of worship, community centers, etc.

SITE: Legal Elements-Includes zoning classifications, FAR, set-backs, height restrictions, allowable site coverage, uses, and parking requirements etc

SITE: Commerce- Includes hotels, restaurants, lounges, cafes, bars, and etc.

SITE: Circulation/Pathways-Includes Residential to Commercial, Residential to Residential, Subways to Residential \& Commercial, Schools to Commercial, etc.

SITE: Circulation/Pathways-Includes Residential to Commercial, Residential to Residential, Subways to Residential \& Commercial, Schools to Commercial, etc.

SITE: Urban Walls -Includes façade patterning, hierarchies, solid/void, rhythm, repetition, etc.

SITE: Climate and Natural Light-Includes natural light intensity, natural light density, analysis over time/space, etc.

SITE: History- Includes neighborhood history. 
Vol. 1, No. 2 Bouratoglou et al.: Global Interaction into the Traditional Design...

Figure 4. Student Work- Examples QILOLCAITLON
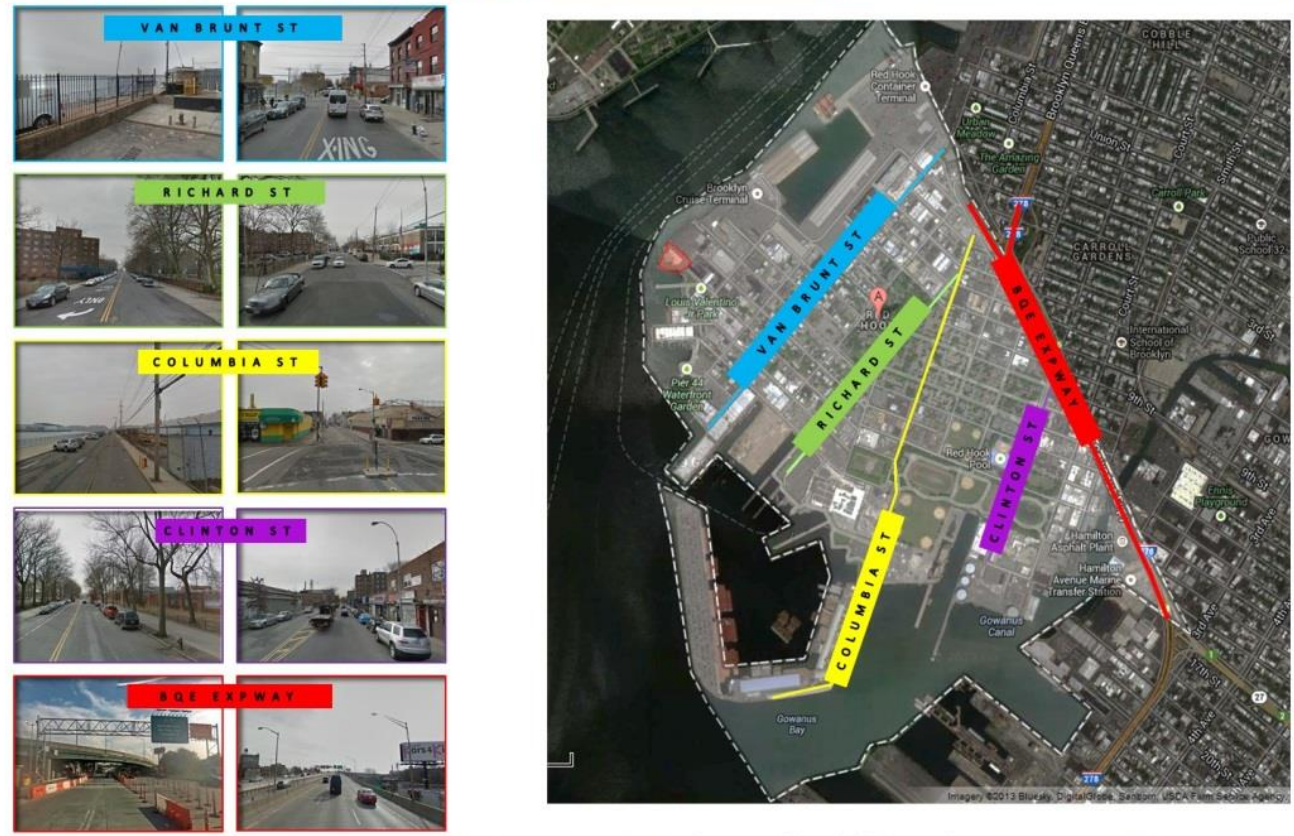

\section{DIORBAAN W'AMTS}

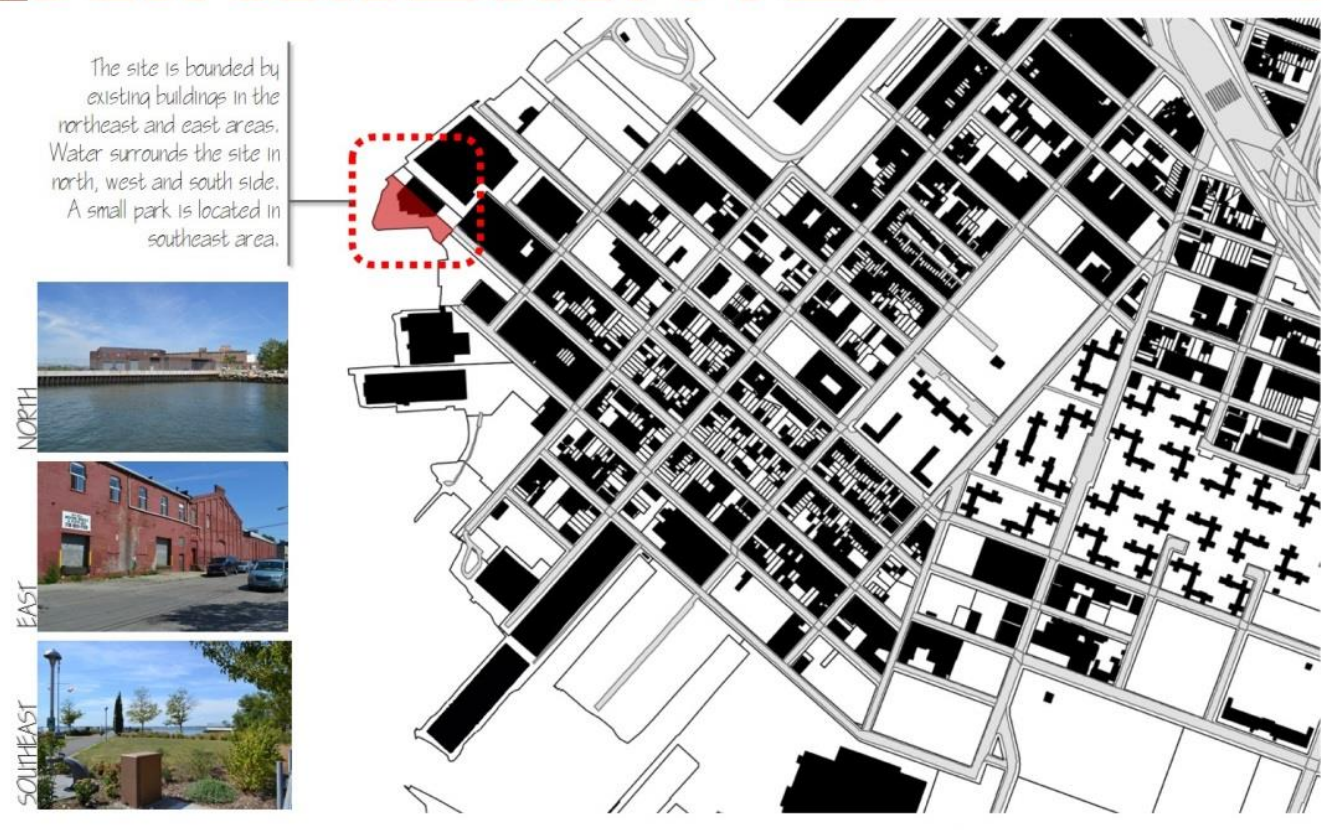




\section{Assignment 1 Site Analysis- Reviews}

Figure 5. Comments

\section{Assignment 1 - Reviews}

\begin{tabular}{ll}
\hline $\begin{array}{l}\text { Phanos (Cyprus) } \\
\text { September 19, 2013 at 1:57 AM }\end{array}$ & $\begin{array}{l}\text { Your site analysis is thorough, well presented and easy to read! Well } \\
\text { done to you and your classmates! The site you chose seems to offer a } \\
\text { variety of challenges as well as opportunities. I am looking forward to } \\
\text { see what you will come up with. }\end{array}$ \\
\hline $\begin{array}{l}\text { Sestember 19, 2013 at 8:35 AM } \\
\text { September 20,2013 at 2:59 PM }\end{array}$ & $\begin{array}{l}\text { Very thorough analysis. It reads well and is easy to follow. Looking } \\
\text { forward to seeing your concept and the project as it unfolds. }\end{array}$ \\
\hline $\begin{array}{l}\text { What is the difference between a boutique hotel and a "normal hotel"? } \\
\text { On a trip to New york last February I stayed in Dream Downtown hotel } \\
\text { and I have to say I found it terribly dissapointing. The rooms are very } \\
\text { standard and small and the circulation is typically long, artificialy light } \\
\text { and ventilated. The plan is the usual double loaded corridor and the } \\
\text { experience is that of being in any mid market hotel anywhere in the } \\
\text { world and sadly not in one of the most exciting cities in the world (in } \\
\text { my opinion anyway) } \\
\text { Not sure what your analysis is trying to achieve. Perhaps looking at } \\
\text { densities of rooms i.e. how efficient in plan are the examples you have } \\
\text { chosen, how many rooms can be accommodated into a certain area, } \\
\text { looking at the analysis of trying to avoid the very efficient double } \\
\text { loaded corridor to achieve a much more pleasant experience for the } \\
\text { visitor to your hotel. } \\
\text { The site looks interesting and the analysis is good, it gives a good } \\
\text { impression for someone who is not familiar with this area. Looking } \\
\text { forward to seeing your ideas develop. }\end{array}$ \\
$\begin{array}{l}\text { Regards, } \\
\text { Graeme }\end{array}$ \\
\hline
\end{tabular}

\section{Assignment 2 Building Typology}

Objective: based on the results of the site analysis, each student will select a building type that they think is appropriate for the site

Structure: Answer the following questions:

Which building type are you researching?

Why are you researching this building?

What is the specialty of this building type you would like to research? i.e. Museum for dance, school for digital media. 
Vol. 1, No. 2 Bouratoglou et al.: Global Interaction into the Traditional Design...

\section{Assignment 2 Student Work}

Figure 6. Student Work

\section{Building Typologies}

1. Which building typology you are researching? A museum

2. Why are you researching this building typology?

This is types of building that I have never done before, and I want to try something that is out of my normal element but create something that is very unique. I also wanted something that wasn't available in the area.

3. What is the specialty of this building type you would like to research i.e.? Museum for dance, school for media. The museums would be for cars of all kind.

4. What are the examples that you will be researching... list the examples, location and architect (10 examples)

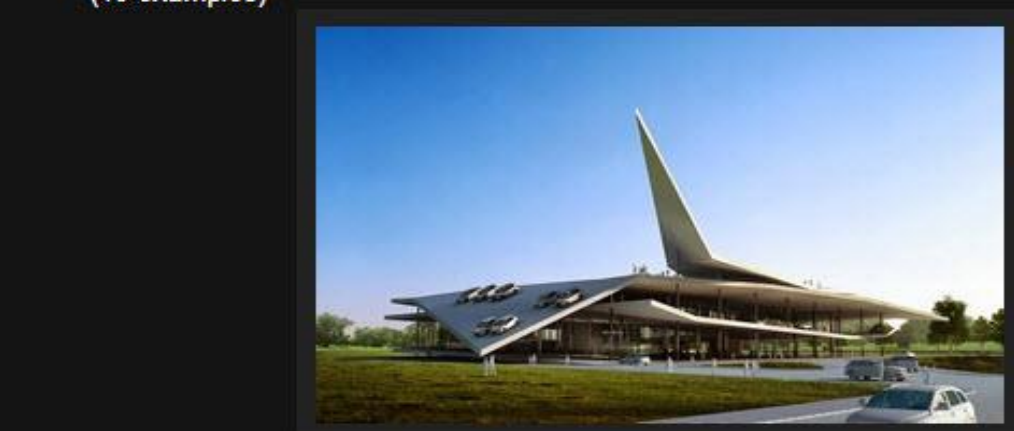

3Gatti Architecture Studio of Rome and Shanghai have won a competition to design an automobile museum in Nanjing, China.

\section{Assignment 2 Reviews}

Figure 7. Comments

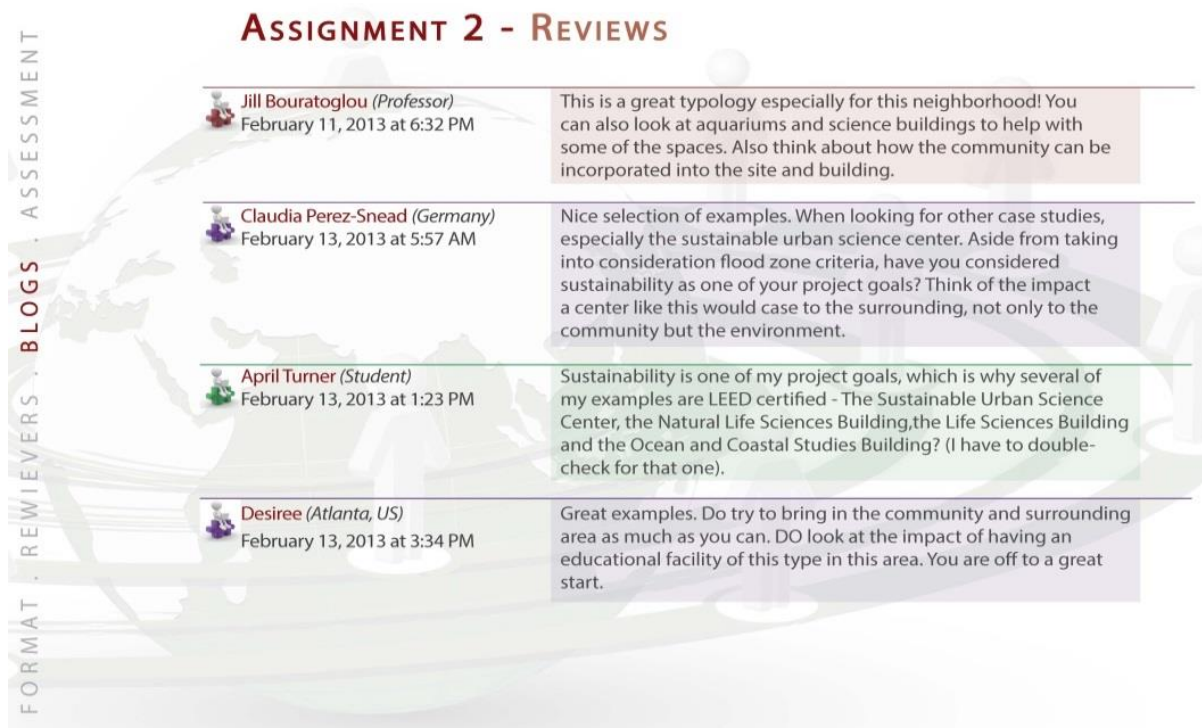




\section{Assignment 3-7 Diagrammatic Analysis}

Objective: Research and gather a minimum of ten examples of the following elements and post your findings to your blog.

Structure: Students are to collect examples of the following elements and use them to create a diagrammatic analysis.

The Students are asked to analyze precedents of the same building typology that they are proposing based on:

Parti- the dominant idea of a building. It is often referred to as the "big idea". It is the main organizing thought behind an architect's design and it is usually represented in the form of a very basic diagram, model or a statement. The objective is to recognize the parti of the particular project.

Massing- the collection of patterns. It is the act of composing 3dimensional forms into a unified and coherent architectural composition.

Symmetry- Bilateral or radial symmetry are explored thru floor plans and elevations

Hierarchy the exploration of the importance or significance of one space versus another (or others)

Geometry- The floor plans, elevations and /or sections can are used to break down the design into simple geometric shapes. Is there additive or subtractive pieces? Using overlays the design is broken down into the simplest geometric shapes

Natural Light- Exploration of how natural lighting enters each building. The images can be of various exterior photographs and/or sections. Orientation of building is critical.

Structure - When we talk about structure we are referring to how is the building standing up? At the very basic level structure is: columns, planes or a combination of those. Structure could be used to define space, suggest movement or develop compositions.

Approach and Circulation- Entrance(s), vertical circulation, and the main circulation throughout the floor plans are identified.

Public versus Private- Public would be the spaces that a any person in this building would have access to. Private would have restricted access. The types of spaces that are private and public will vary from building type to building type.

Space Organization- Buildings are composed of a lot of spaces. Those spaces are usually organized based on their function or use. Based on those diagrams you should get a clear understanding on how a particular type of building is organize

The building or any example is reduced to its bare essentials. Each student creates diagrams of the their precedents. 
Vol. 1, No. 2 Bouratoglou et al.: Global Interaction into the Traditional Design...

Figure 8. Milk and Cookies

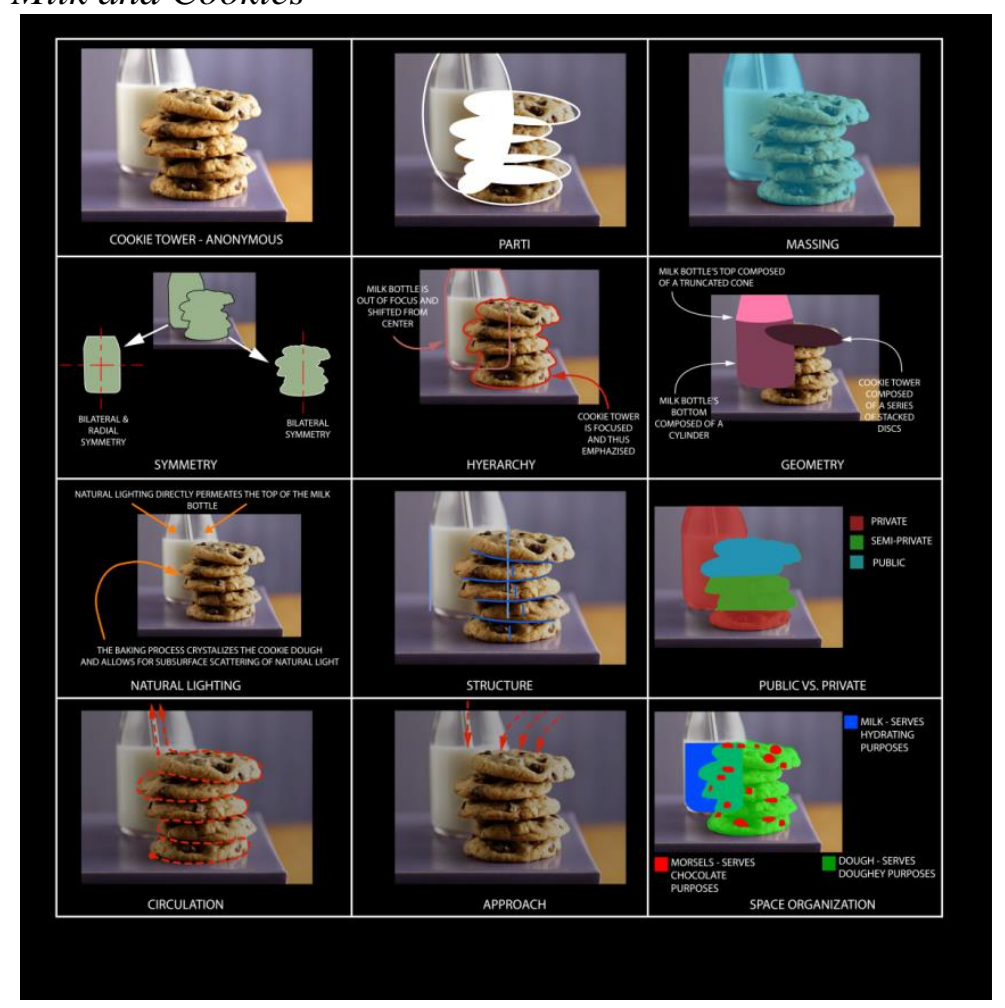

Assignment 3-7 Diagrammatic Analysis - Student Work

Figure 9. Diagrammatic Analysis Student Work

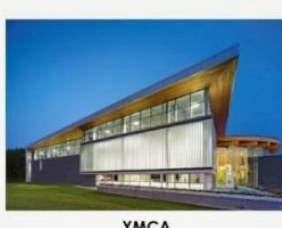

YMCA
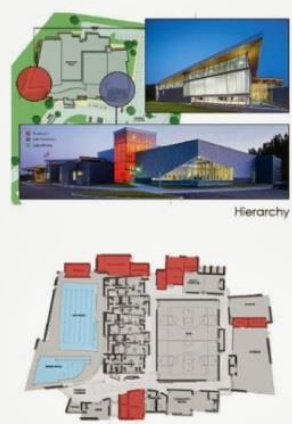
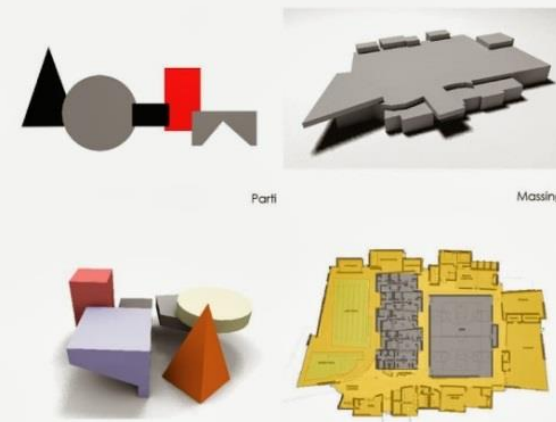

Notural Light

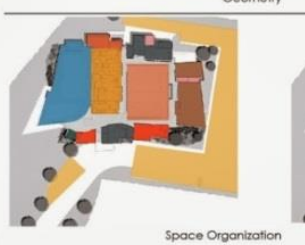

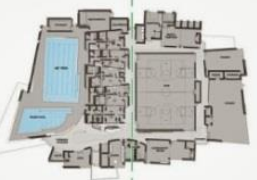

Symetry/Ballance
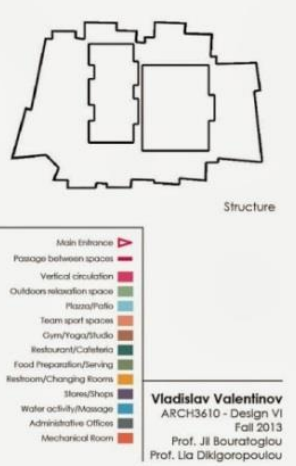


\section{Assignment 3-7 Diagrammatic Analysis - Reviews}

Figure 10. Comments

Assignments 3 to 7 - Reviews

\begin{tabular}{|c|c|}
\hline $\begin{array}{l}\text { Lia Dikigoropoulou (Professor) } \\
\text { September 27, } 2013 \text { at 7:50 PM }\end{array}$ & $\begin{array}{l}\text { Great work. Your diagrams are very clear. I can't wait to see how all } \\
\text { these will come into play into your own building }\end{array}$ \\
\hline $\begin{array}{l}\text { Andy Fastman (California, US) } \\
\text { September 27, } 2013 \text { at 10:03 AM }\end{array}$ & $\begin{array}{l}\text { Incredible analyses. To be } 100 \% \text { frank, I do not have it in me to } \\
\text { reread thoroughly enough to find a point to critique. I am equally } \\
\text { stoked to see how you use this knowledge deployed into your } \\
\text { facility. }\end{array}$ \\
\hline $\begin{array}{l}\text { Lia Dikigoropoulou (Professor) } \\
\text { September 27, } 2013 \text { at 10:33 AM }\end{array}$ & Coming from Andy, this is such a great compliment!!!! \\
\hline $\begin{array}{l}\text { Loukia Tsafoulia (New York, US) } \\
\text { September 27, } 2013 \text { at 3:40 PM }\end{array}$ & $\begin{array}{l}\text { Yes! Very good job! This summary is a great starting point for your } \\
\text { own creation. Keep whatever you learned through that process } \\
\text { in terms of clean visualization, appealing and straightforward } \\
\text { diagrams, written explanation of ideas and criticism. Implement } \\
\text { all these throughout your design process. Looking forward to see } \\
\text { what's next! }\end{array}$ \\
\hline $\begin{array}{l}\text { Vladislav Vanlentinov (Student) } \\
\text { September 27, } 2013 \text { at 8:58 PM }\end{array}$ & $\begin{array}{l}\text { Thank you all, I feel that you are spoiling me. } \\
\text { I can't hardly wait to start designing. I promise that I will not only } \\
\text { try not to disappoint you, but will do my best to provide imaginary } \\
\text { visitors with the most amazing and comfortable imaginary facility. }\end{array}$ \\
\hline $\begin{array}{l}\text { Hector (New York, US) } \\
\text { September 28, 2013 at 4:46 AM }\end{array}$ & $\begin{array}{l}\text { Great work Vlad! Don't think of it as an imaginary facility though. } \\
\text { You never know if someone would take a look at the ideas a few } \\
\text { years down the road and decide it to be a good investment. } \\
\text { Never put yourself down. }\end{array}$ \\
\hline
\end{tabular}

\section{Assignment 8 Programmatic Analysis}

Objective: Based on your precedent studies, determine the program of your building.

Structure: Develop Relationship Diagram:

Adjacency Matrix:_A chart that provided the space relationship and criteria to the other spaces within the building. The purpose of the matrix is to organize and link different activity areas together.

Criteria Matrix: Attempts to organize the design program requirements in a concise form.

\section{Assignment 8 Programmatic Analysis -Student Work}

Figure 11. Adjacency Matrix

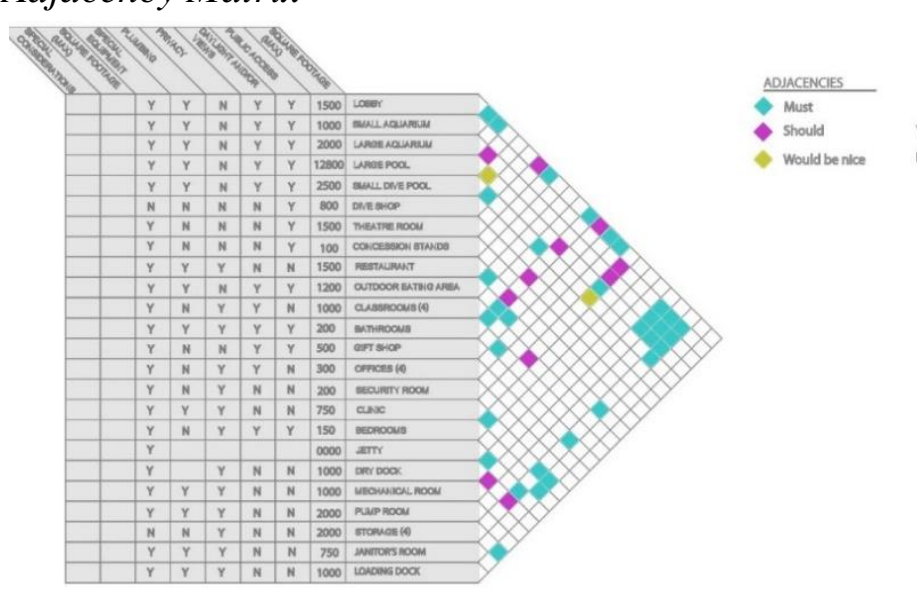


Figure 12. Bubble Diagram
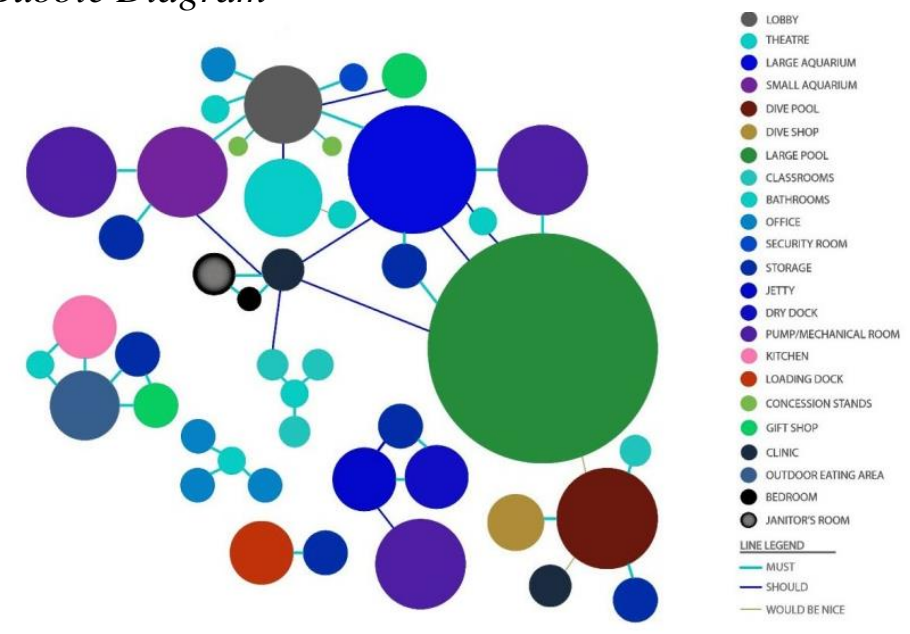

\section{Assignment 8 Programmatic Analysis -Reviews}

Figure 13. Comments

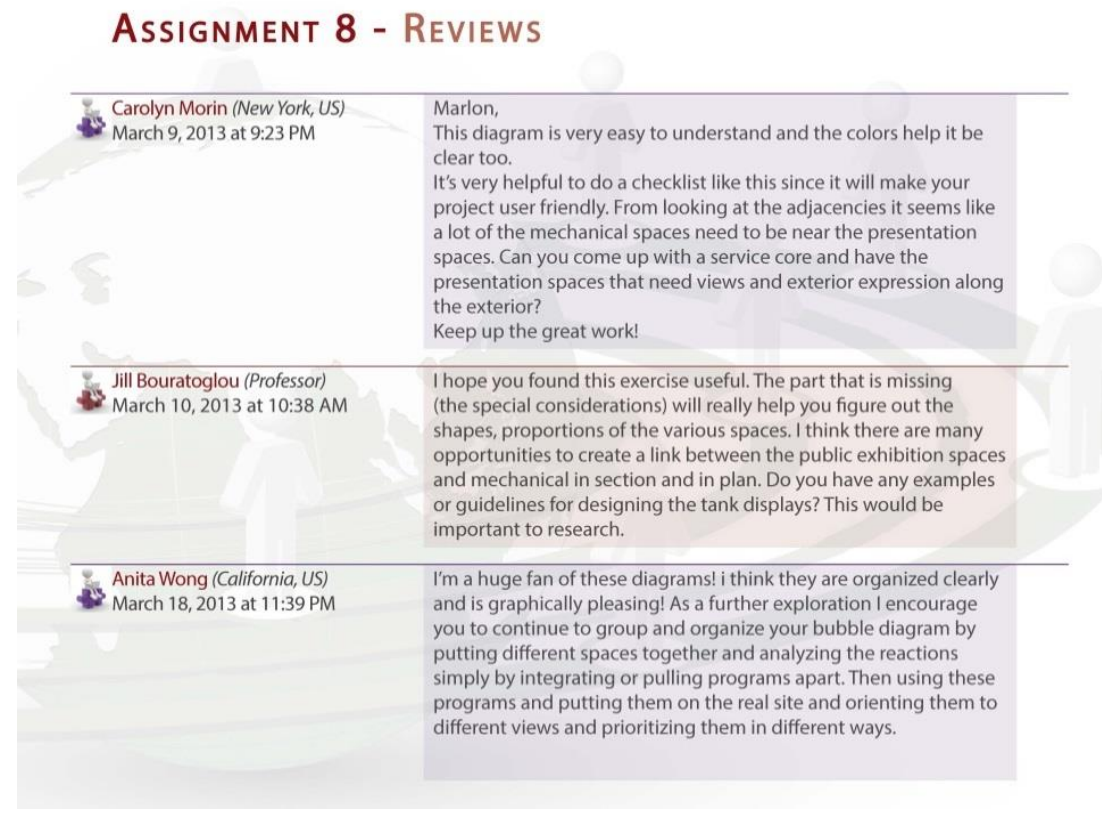

\section{Assignment 10 Concept Collages}

Objective: Concept Design

Structure: The Collages should have images that inspire, show different outlines, scales, details and materials.

- One collage based on your impression of the site you have selected (not images of the site) 
- One collage based on a word selected for the semester: trendy, impact, dismantle, historic, potential, rustic, renewal, scenic, isolated, flooded or deserted

- One collage based on the program of your project

\section{Assignment 10 Concept Collages - Student Work}

Figure 14. Student Work
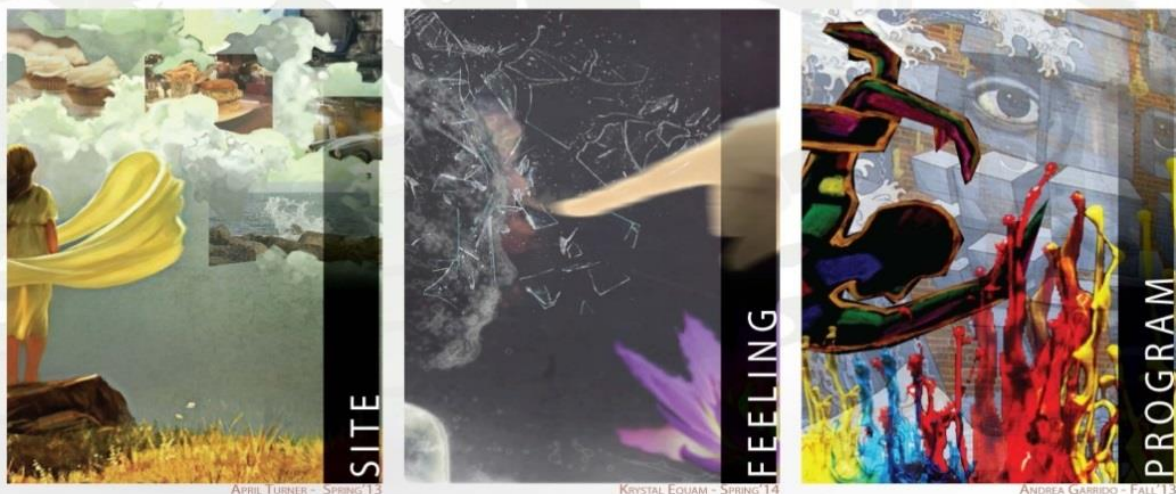

\section{Assignment 10 Concept Collages - Reviews}

Figure 15. Comments

\begin{tabular}{|c|c|}
\hline $\begin{array}{l}\text { Heriberto Velazquez (Student) } \\
\text { April 3, } 2013 \text { at 12:44 PM }\end{array}$ & $\begin{array}{l}\text { I actually have been working on hybrid models and while creating } \\
\text { them, certain aspects popped up that I had no intention of } \\
\text { creating. While I do try to have meaning behind everything i create } \\
\text { in my models, i try to have that meaning be different to different } \\
\text { people who see it. } \\
\text { As for the brain in my collage, I used it to represent the "Single } \\
\text { Mindset" that the programs in a community center have which is to } \\
\text { help and enrich the community around it. Homer Simpson on the } \\
\text { other hand, I used him to represent popular followings in a culture } \\
\text { which is what I believe Brooklyn is about and Homer Simpson in a } \\
\text { way has had a strong impact on the culture of NYC and people who } \\
\text { are part of the culture are all connected because of what they like } \\
\text { and dislike. }\end{array}$ \\
\hline $\begin{array}{l}\text { Eugenio Dos Santos (Portugal) } \\
\text { April } 3,2013 \text { at } 10: 44 \text { AM }\end{array}$ & $\begin{array}{l}\text { Earlier i meant to say study models instead of collages * }(\mid \text { see you } \\
\text { have been working these themes in your collages })^{*}\end{array}$ \\
\hline $\begin{array}{l}\text { Elena Pazardjievska (Macedonia) } \\
\text { April 3, } 2013 \text { at 5:09 PM }\end{array}$ & $\begin{array}{l}\text { Your collages are too symbolic and too narrative. If you had a cold } \\
\text { kind of feeling, the feeling can not be described by a glass of cold } \\
\text { water, it is too naive. Also, NYC has a lot of popular culture icons } \\
\text { and Homer Simpson is surely not one of them. Please try to use } \\
\text { different signs and try to apply deeper philosophy on your project. }\end{array}$ \\
\hline
\end{tabular}

\section{Assignment 11 Concept Models}

Objective: Concept development

Structure: Concept model should have a 3"x3" base and be constructed from a wide variety of materials. 
The material used in creating these models should be chosen based on what it represents in your collages. There will be three different models per collage for a total of three collages and nine models.

\section{Assignment 11 Concept Models - Student Work}

Figure 16. Student Work
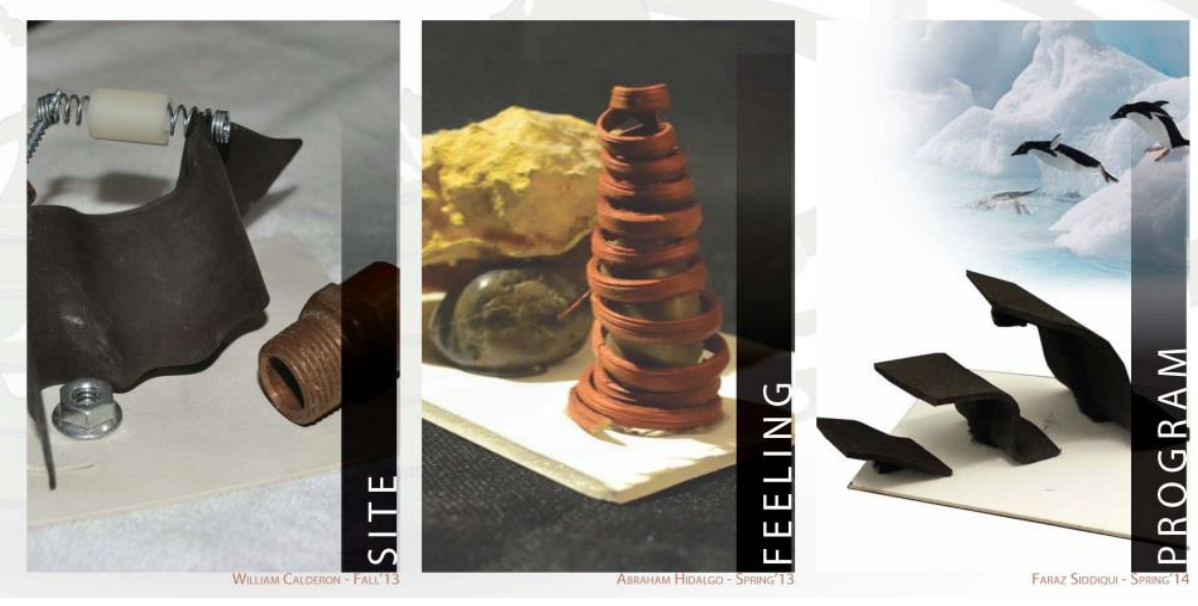

\section{Assignment 11 Concept Models- Reviews}

\section{Figure 17. Comments}

\section{Assignment 11 - Reviews}

\begin{tabular}{|c|c|}
\hline $\begin{array}{l}\text { St. Metakaos (Australia) } \\
\text { October 29, } 2013 \text { at 6:48 AM }\end{array}$ & $\begin{array}{l}\text { Your models are very abstract, I really appreciate how you have } \\
\text { put concept in motion and made many examples which are very } \\
\text { playful. I would encourage you to go even further but not without } \\
\text { placing human scale models and plants and trees as part of the } \\
\text { composition. Be honest about the number of people and the } \\
\text { center of attraction (ie the performance arts program) you will be } \\
\text { simulating through your model, as in if there are only a handful of } \\
\text { people then also look at what its like with } 1000 \text { 's of people. Make } \\
\text { sure your model people are decent so your photography picks up } \\
\text { the atmosphere that people bring. Keep zooming between the } \\
\text { macro and micro effects of your architecture, great work \& well } \\
\text { done... }\end{array}$ \\
\hline $\begin{array}{l}\text { Paul Adamson (California, US) } \\
\text { December 1, } 2013 \text { at 5:50 AM }\end{array}$ & $\begin{array}{l}\text { These are quite expressive. and varied. I wonder if you have a } \\
\text { preference for either of the formal compositions? The white wedge- } \\
\text { shaped model has the most architectural potential, but any might } \\
\text { be translated with more or less transformation. }\end{array}$ \\
\hline $\begin{array}{l}\text { Candy Soller (Australia) } \\
\text { December 1, } 2013 \text { at 6:06 PM }\end{array}$ & $\begin{array}{l}\text { I am enjoying the fact that you are being abstract in your } \\
\text { emotional interpretation of the site. hold onto it and see if you can } \\
\text { reinterprete it in the built form. }\end{array}$ \\
\hline
\end{tabular}

\section{Assignment 12 Hybrid Model}

Objective: Concept Development 
Structure: From your Study Models you will generate a hybrid model that takes the best qualities of your models.

This Hybrid model should come after all revisions by your professors, critics and peers to the initial study models have been completed.

\section{Assignment 12 Hybrid Model - Student Work}

Figure 18. Student Work

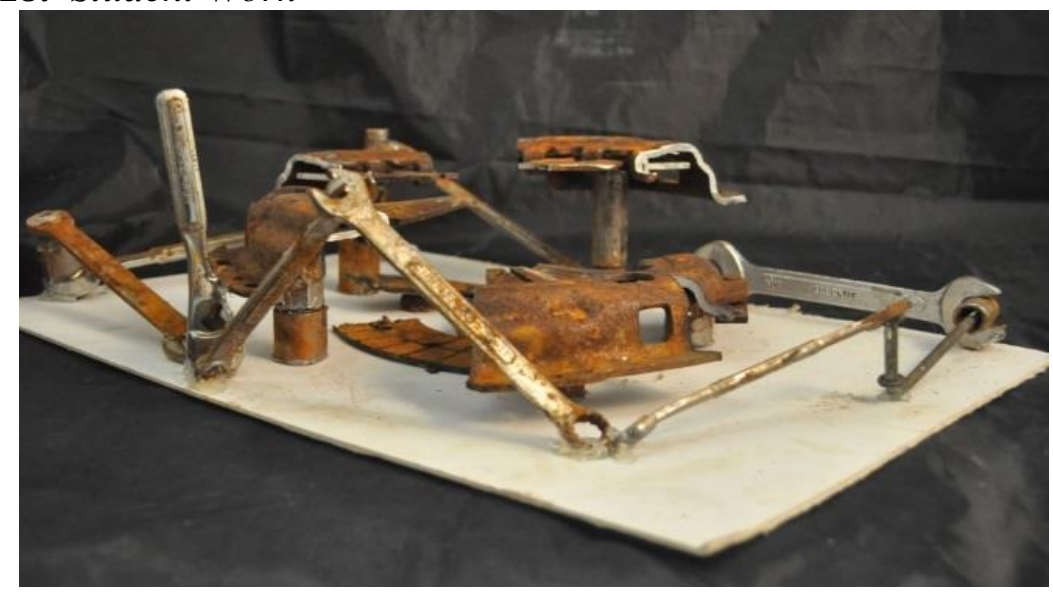

\section{Assignment 12 Hybrid Model - Reviews}

Figure 19. Comments

\section{Assignment 12 - Reviews}

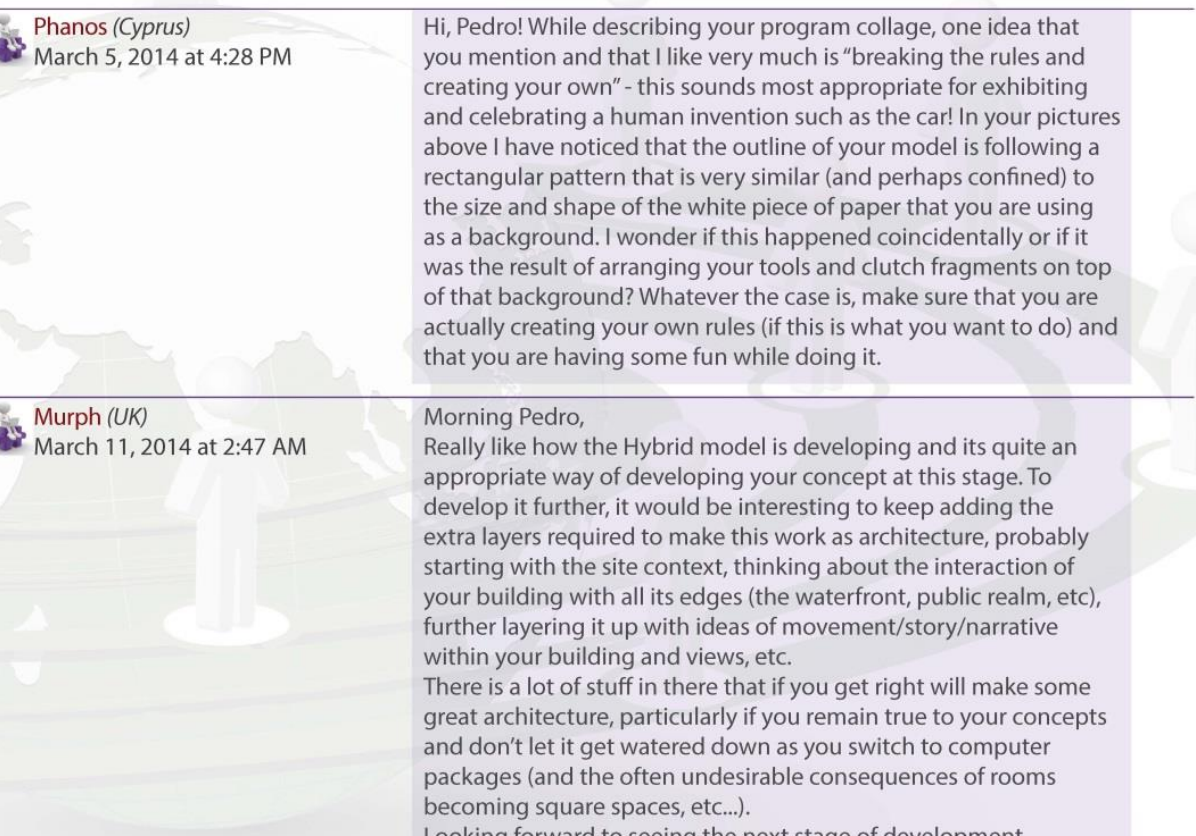

Looking forward to seeing the next stage of development. 
Vol. 1, No. 2 Bouratoglou et al.: Global Interaction into the Traditional Design...

\section{Assignment 13 Massing}

Objective: Using your conceptual model and develop a massing model that is to the scale of the site

Structure: The scale of the site model is: $1 / 32$ " $=1$ ' -0 ". This model should take into consideration your studies of exterior circulation as well as your concept and development up to date.

It should also approximate the actual size of your development in relationship to the neighboring context.

\section{Assignment 13 Massing- Student Work}

Figure 20. Student Work

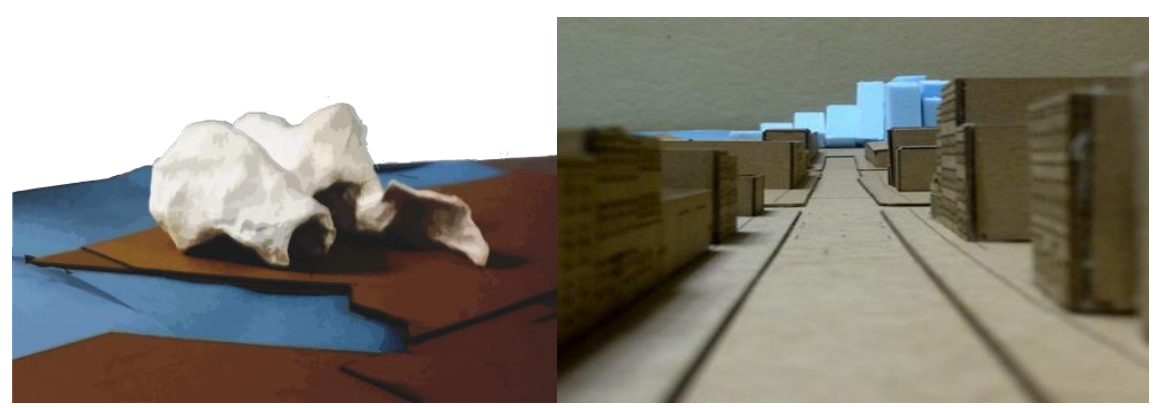

\section{Assignment 13 Massing - Reviews}

Figure 21. Comments

\begin{tabular}{ll} 
ASSIGNMENT $13-$ & R EVI E WS \\
April 15, 2013 at 2:39 PM & $\begin{array}{l}\text { Strong perspective. I like how the building seems to unfold in front } \\
\text { of me in this view. It will definitely draw people in due to curiosity } \\
\text { of what is going on behind the buildings. My impression also is that } \\
\text { the structure will be massive. It just my opinion based on how it } \\
\text { looks to me now. }\end{array}$ \\
$\begin{array}{ll}\text { David Wu (Student) } \\
\text { April 15, 2013 at 3:12 PM }\end{array}$ & $\begin{array}{l}\text { I've a very interesting massing. I'm curious in seeing how the rooms } \\
\text { will be like, since there is a gradual slope. I've done a similar project } \\
\text { like this and the slope may be a problem for you later on. Good job! }\end{array}$ \\
\hline $\begin{array}{l}\text { April 15, 2013 at 3:29 PM } \\
\text { April 15, 2013 at 4:24 PM }\end{array}$ & $\begin{array}{l}\text { The massing of your structure is extremely interesting and eye- } \\
\text { catching. I really like how it resembles a wave but also has the } \\
\text { outline of your shell in all your views. Great job on making a } \\
\text { statement on the site. }\end{array}$ \\
\hline $\begin{array}{l}\text { Eldon Ralph (Student) } \\
\text { Absolutely love the first image of the street level and the building. }\end{array}$ \\
$\begin{array}{l}\text { I think casual sloping of the mass is a very strong and interesting, } \\
\text { but its seems to be very large. I'm very curious to see how the } \\
\text { building looks at the end of the semester. Keep up the good work.! }\end{array}$
\end{tabular}

\section{Assignment 14-17 Diagrammatic Studies}

Objective: Based on your existing programming and your concept massing study create diagrammatic plans and sections. 
Structure: Creating diagrammatic plans and sections that connect the bubble diagrams and the conceptual massing. The massing must be shown in the site in the context of the neighborhood.

\section{Assignment 14-17 Diagrammatic Studies- Student Work}

Figure 22. Student Work

\section{Assignment 14 to 17 - Student Work}
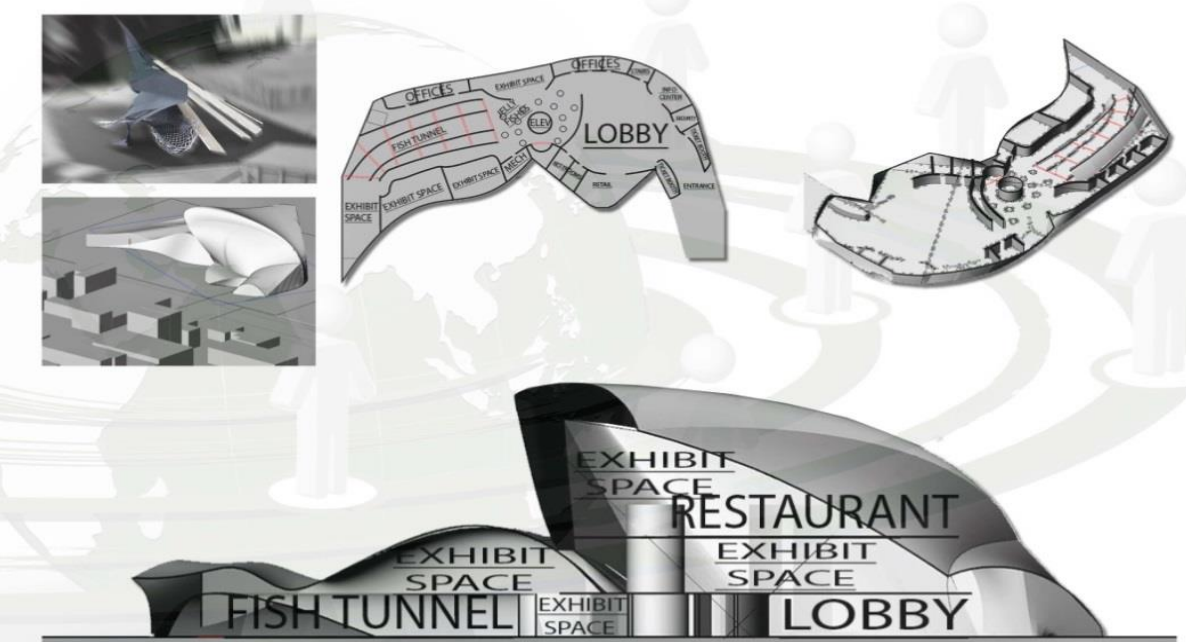

\section{Assignment 14-17 Diagrammatic Studies- Reviews}

Figure 23. Comments

Assignment 14 to 17 - Reviews

Lia Dikigoropoulou (Professo

The first thing I checked was flow of spaces. An aquarium is just like a museum. you want it to flow without getting lost. You need to move from one exhibit to the next without asking the question
"where do I go from now on?" There should be a connection from the beginning to the end.

Andy Fastman (California, US) It is always a big jump from pure collage/parti study to 3-D model without some diagramming and sketching in between. If you are more comfortable in digital evolution (although your physical modeling skills are quite keen), think simpler at first. Block out and extrude volumes to represent your programmatic elements. Play with them in the computer to test arrangements and relationships. Never forget the sectional relationships in addition to the planometric moves.

Lia is right, an aquarium is a curated somewhat narrative and completely proscribed path. The HOW (you get there) is as important as the Where (you end up) and all are trumped by the WHY (it matters). Take a step back and look at several aquarium precedents again for their organizational approach. Notable promenades through such spaces are the Boston (New England) Aquarium by Cambridge Seven, the Baltimore (National) Aquarium by I.M.Pei and the Atlanta (Georgia) Aquarium by Peckham Guyton Albers \& Viets Inc. and of course, the Monterey Bay Aquarium by Esherick Homsey Dodge \& Davis. THese all have unique circulatory paths and systems which are worth taking a look at. Also, run downtown and have a fresh look at the Guggenheim. I think the gallery spaces need no introduction. 


\section{Assignment 18 Refining Plans and Sections}

Objectives: Refinement of Massing Studies with a focus on circulation throughout the building

Structure: Refine your plans and sections using volumes as created by your massing, focusing on circulation throughout the building. This should include connections to the outside of the building as well as exterior circulation routes (pedestrian, vehicular drop off/pick up, etc.), ADA mobility requirements \& fire egress requirements.

\section{Assignment 18 Refining Plans and Sections- Students Work}

Figure 24. Students Work
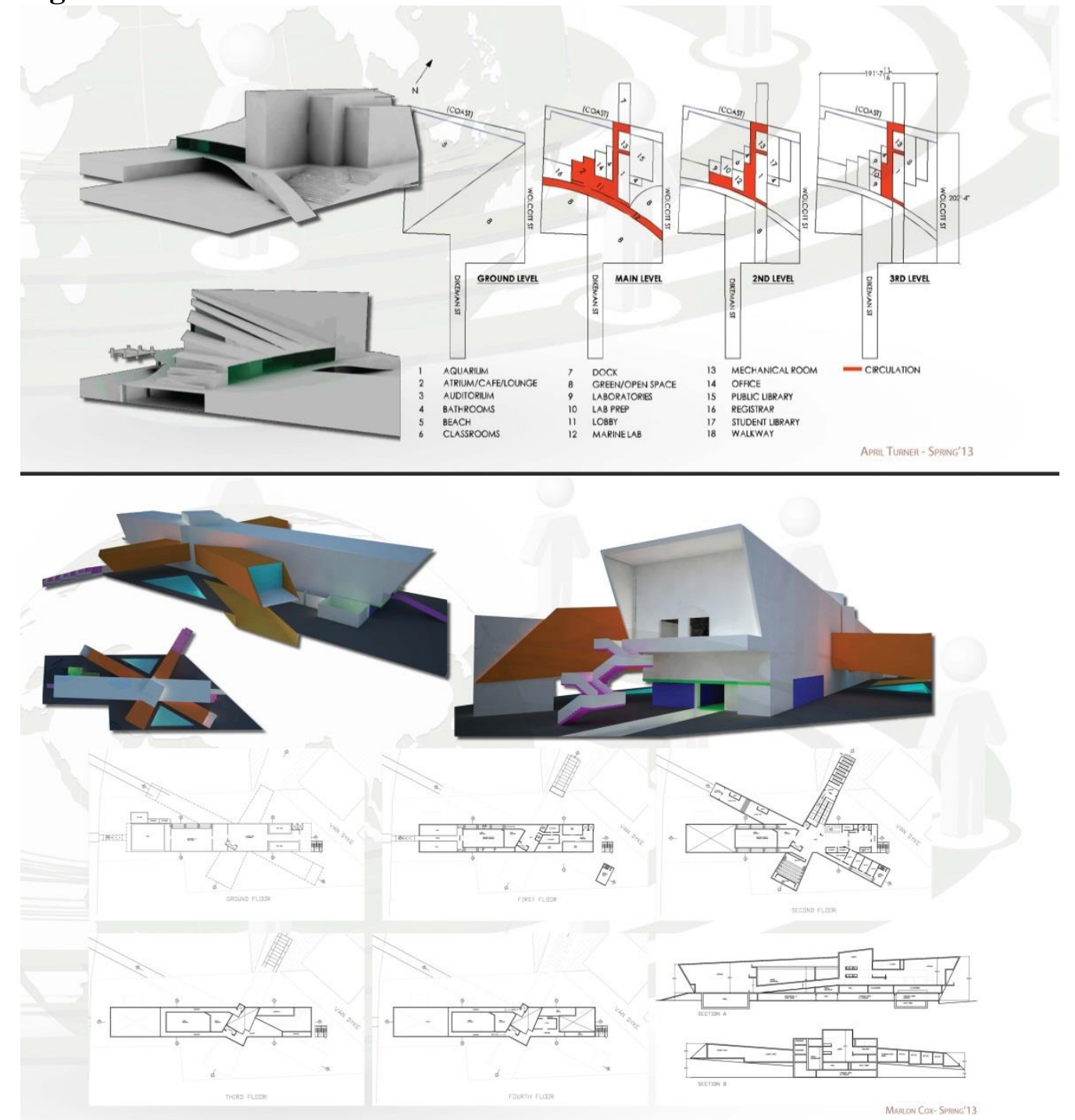


\section{Assignment 18 Refining Plans and Sections- Reviews}

Figure 25. Comments

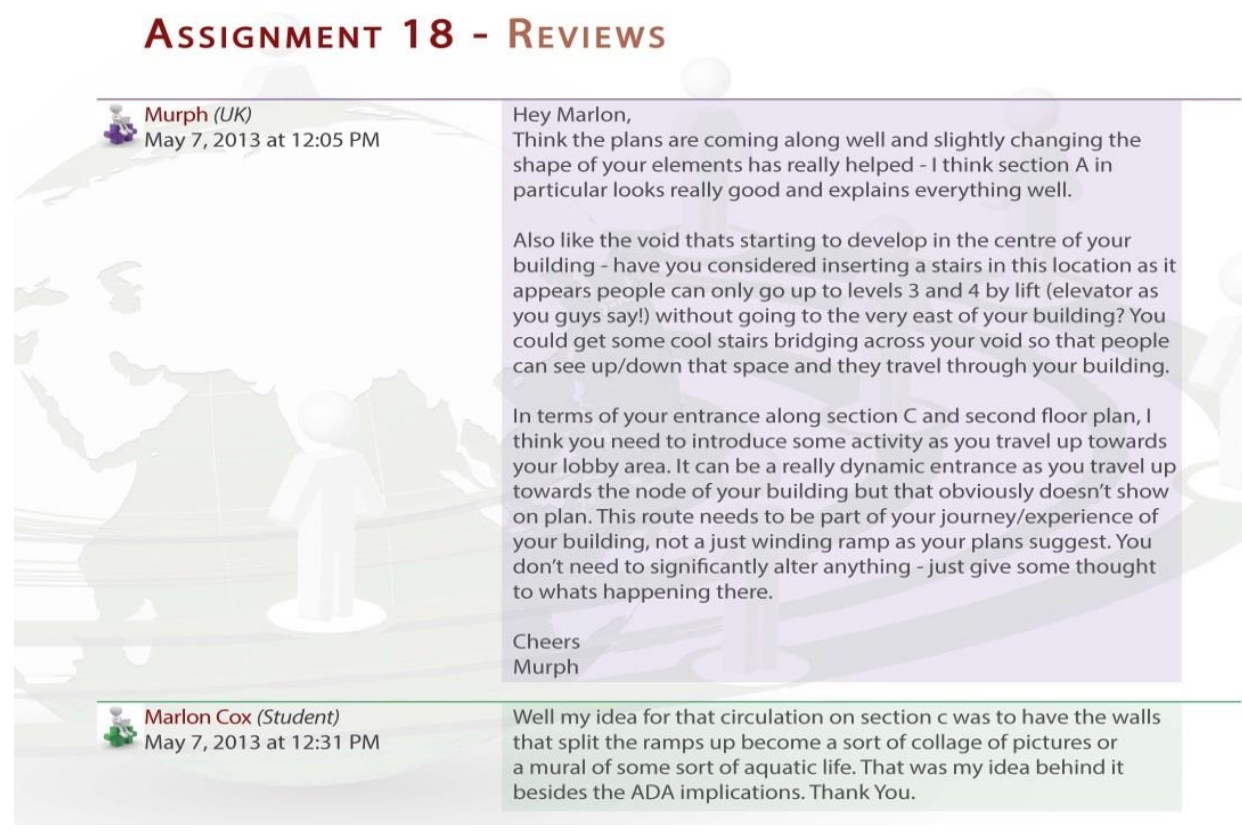

\section{Assignment 19 Elevations and Fenestration}

Objective: Further develop your project with façade studies and elevations studies.

Structure: Your elevations should include any façade treatments as well as materials incorporated, but most importantly it must include the immediate context of your building. Your building is on a predetermined site, not floating amidst infinite space. At this stage you should also explore materials for your building.

\section{Assignment 19 Elevations and Fenestration- Student Work}

Figure 26. Students Work

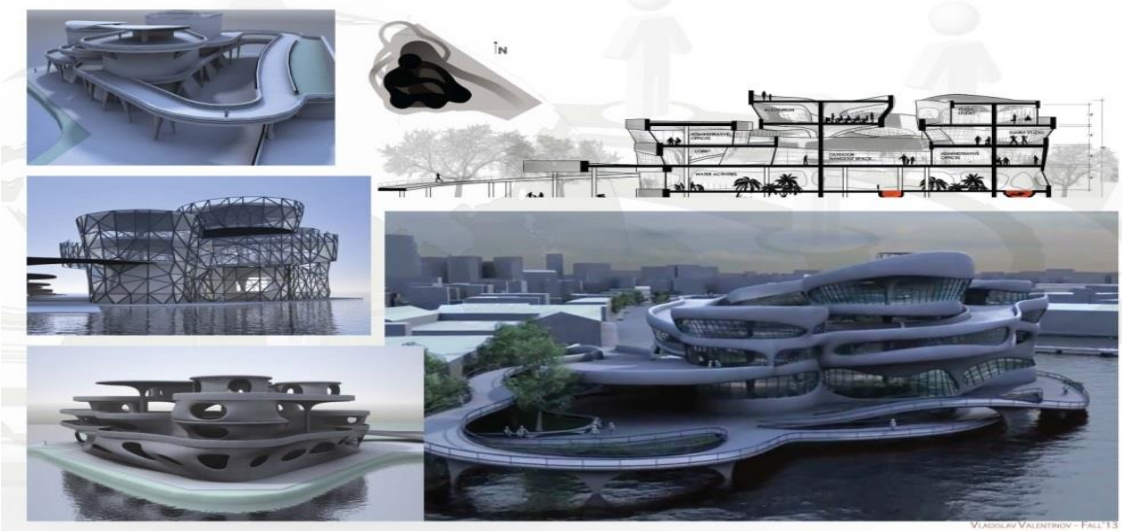




\section{Assignment 19 Elevations and Fenestration- Reviews}

\section{Figure 27. Comments}

\section{Assignment 19 - Reviews}

Loukia Tsafoulia (New York, US) Hello Valentinov,

November 28, 2013 at 9:33 PM

This is certainly a far better approach that the triangulated one. The whole ribbon idea respects more the fluidity and organicity of your forms.

Is is also interesting how you place these three images together trying to see what you learned in the past and how you are moving forward. Well the very first 'swiss cheese' approach although a bit naive and unresolved as a system still has a very interesting feeling of enclosure and playful understanding of interior vs exterior.

It still seems to me that in your last attempt all of the spaces are EQUAL in terms of experiences. But ask your self: What are the more intimate, private, mystical enclosed spaces versus the more public ones, both exposed and open to the great views of the site?

I am sure that your program has these experiencial dipoles that your skin still does not convey.

Reveal all these particularities: Introversy vs extroversy, public vs private, dark and moist vs open and bright, social vs contemplative ground vs sky.

The program should inform your skin and vice versa your skin should help the program. Develop your proposed skin in such a way that hierarchize spaces a bit more rigorously.

You are getting there!!!

Lla Dikigoropoulou (Professor) November 28, 2013 at 11:24 AM

\section{I totally agree with Loukia. What is private and what is public,} should dictate the opacity or transparency of your spaces. Love the progress. I am so happy you did not just stick with one solution, and you are constantly exploring. Happy Thanksgiving!

Andy Fastman (California, US) November 28,2013 at 5:28 PM

This investigation is compelling. The direction is far better. Although the perforations are not yet there, something is starting to gel better than the fractured glass skin.

The ground interface is not there at all. Go back through your previous interations and look at which ground strategies were more successful. For arguments sake, look at the post Katrina proposals for hurricane-proof residential dwellings. Several arhitects participated....and Brad Pitt was involved (happy googling). There were some incredible grade interface solutions to allow water to drain. Also look at the horribly cliche resorts on stilts in Tahiti and Bora Bora. Although the architecture is unremarkable, there is a quality to a hovering mass over water that you could learn from.

\section{Assignment 20 Final Design}

At the end of the semester, the students present their blog to the jury. Everything they have been working on has been recorded and presented. 
Figure 28. Students Work

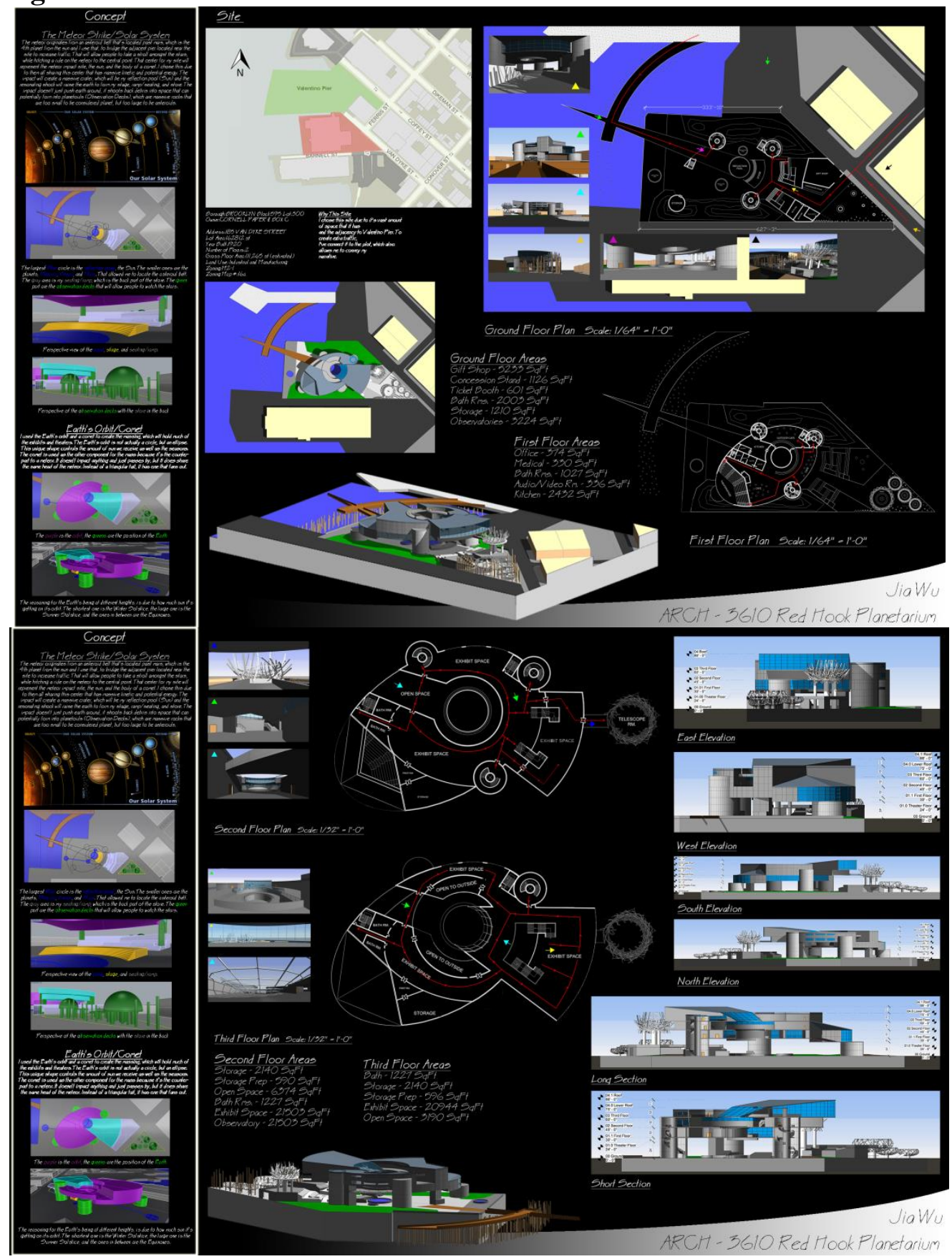

\section{Assessment Request}

At the end of the semester a thank you note is sent to all the on-line reviewers with request for feedback. 
Figure 29. Feedback Request

\section{Assessment - Request}

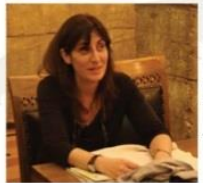

Lia Dikigoropoulou

prof.liamd@gmail.com

Jan 23rd 2013

Hello All,

Last semester, you volunteered to be on-line reviewers for my theoretical design class. I know it was not perfect. It was actually a struggle to convince students to post on their blogs. But despite of that, your comments and input were greatly appreciated. THANK YOU SO MUCH!!!!!

The next semester is going to start again Jan 28,2013 , and I would like to try this again. The class has changed a bit, and it is no longer an elective. It is a required class, and we have 15 students signed up. The class is called Advance design and the students are in their sixth semester.

If you are willing to commit virtually again for this coming semester I will forward you the new syllabus and more information about the course. Just let me know so I can start the process. If you would like more than one student let me know.

Also if you have any comments or suggestions on how to improve the course and or the process feel free to let me know.

We are here to learn and improve and make it a better global learning experience for our students.

\section{Assessment Responses}

Figure 30. Responses

Assessment - Responses

Kristen Van Haeren

kristenvh@hotmail.ca

British Columbia, Canada)

Jan 23 Hi Lia,

Last semester was a wonderful experience to see student work. I
would love to participate again. Only improvements I can think would love to participate again. Only improvements I can think of is if there is more background reasoning from the student for their designs. Sometimes it seemed that they jumped from one stage to another. I would also like to see more student process or sketching work or even small written concepts/blurbs. Having the students creatively express their thoughts and projects through a variety of mediums I think can help us as reviewers understand their projects, and them as students to focus their intentions. Looking forward to another semester.

Thanks again,

Kristen

Andrew Neal David Lia-

astman, AIA LEED A.P. BD+C (Califormia, United States) Jan 24

I'd love to do it again. I could probably handle more than one if you need. As I have a bit more time, I'll throw a couple of suggestions at you based on my experience last semester, or I can review the syllabus and comment globally. Also, I realize that I pushed Jessic pretty hard last semester. I did my best to keep it completely constructive. I am hoping that the level of commentary was up to your expectations.

Andy 


\section{Conclusion}

Teaching is not only creating and developing new courses, but also implementing new ideas in the classroom. We are always exploring different ways to engage and inspire our students. Using blogs in this studio has allowed our students to be connected with professionals. They have created a symbiotic relationship, sharing ideas and criticism while allowing the student project to develop much further. This process benefits not only the student, but also the professional that can mentor future architects and teach from their desk, while working in the field. This process keeps the comments and development of the projects relative to what is being done in the field.

This is a unique and innovative way of connecting a design studio with professionals from all over the world and give exposure to our students to an alternative thought process.

\section{References}

Clark, Roger H., and Michael Pause. Precedents in Architecture. New York: Van Nostrand Reinhold, 1985. Print.

Ching, Frank. Architecture: Form, Space, and Order. Hoboken, N.J: John Wiley \& Sons, 2007. Print

Panero, Julius and Martin Zelnik,Time-Saver Standards for Interior Design and Space Planning, 2nd Edition 
